\title{
Incorporating the social environment in genotype environment interaction studies of mental disorders
}

\author{
That both genetic (nature) and environmental (nurture) \\ factors contribute to the aetiology of depression and other \\ common mental disorders is well recognised. However, the \\ study of gene-environment interaction $(G \times E)$ in mental \\ disorders has recently incited a great deal of controversy. We \\ have suggested (1) that what is needed is more, and better \\ quality, rather than less, research on how genotypes and a \\ range of environmental factors jointly produce mental \\ disorders. In particular, we believe that the non-replication \\ of genetic main effects and $\mathrm{G} \times \mathrm{E}$ in mental disorders may be \\ explained at least in part by the lack of consideration of \\ relevant social environmental contexts.
}

\section{The controversy}

In 2003, Caspi et al. (2) published a groundbreaking article which found that a common variable number of tandem repeats polymorphism in the promoter region of the serotonin transporter gene (SLC6A4), designated as 5-HTTLPR, moderated the relation between stressful life events and depression. Specifically, individuals possessing one or two copies of the short (s) 5-HTTLPR allele that is less transcriptionally efficient than the long (1) allele (3), had higher levels of depression and suicidality in the context of recent life stressors. This article was lauded in the scientific [Behavioural Genetics. Getting the short end of the allele (4)] and popular press [Tapping the Mood Gene (5)]. The study offered the hope that consideration of environmental factors would improve our ability to identify genes that increase the risk for depression, and for mental disorders more broadly. At the same time, the results suggested that certain genetic factors increased risk of mental disorders only in the context of an adverse environment thus providing encouragement to researchers whose primary focus was the role of the environment and who felt bruised and neglected in the much proclaimed 'Genomic Era.(6-8)' Caspi et al. (2) has been cited 1669 times at this writing and hundreds of empirical $\mathrm{G} \times \mathrm{E}$ studies (42 examining the interaction between the 5-HTTLPR locus and adverse environments in risk of depression) have been published, concerned with a wide range of behavioural phenotypes from depression and antisocial behaviour to substance abuse and smoking.

Enthusiasm for $\mathrm{G} \times \mathrm{E}$ studies of mental disorders was recently brought into question by Risch et al.'s (9) meta-analysis that found no evidence for significant interaction(s) between 5-HTTLPR genotype and stressful life events in risk for depression. Based on their analysis, Risch et al. (9) critiqued the $\mathrm{G} \times \mathrm{E}$ approach stating 'Despite the lack of valid confirmation of the Caspi et al. results, the approach to implicate candidate genes that had failed previous direct association studies through inclusion of an environmental exposure has been rapidly embraced, and substantial resources have been devoted to subsequent research'. They concluded that the study of G $\times$ E interactions in psychiatric disorders should await the identification of 'robust marginal gene associations'. Like the original Caspi et al. (2) report, the Risch et al. (9) article received widespread attention in the scientific [Much Touted 'Depression Risk Gene' May Not Add to Risk After All (10) and popular press Report on Gene for Depression Is Now Faulted (11)]. The result has been much confusion amongst lay persons and debate amongst scientists as to how best to study the role of both genetic and environmental factors in the aetiology of depression.

Unfortunately, the framing of this controversy in both the scientific and lay media has fueled the growing polarisation between two groups of scientists who share the common goal of disentangling the aetiology of common mental disorders but are focused on different research questions. The first are the geneticists who aim to discover new gene-disorder associations and use agnostic genome-wide association study (GWAS) methods to do so. The second are the researchers (typically developmental psychopathologists and psychiatric epidemiologists) who aim to understand how variation in candidate genes explains differential vulnerability to environmental risk factors. Although both groups bring important insight to the study of factors that contribute to commonly occurring mental disorders, missing from both approaches is a consideration of how the social environment may modify genetic effects on mental illness.

\section{The social environment modifies genetic effects on common mental disorders}




\section{The social environment and mental disorders}

The social environment refers to characteristics of individuals' local environment that may be determinants of mental disorders and are independent of individual characteristics. Social environmental characteristics may be compositional aggregates of individual-level characteristics (e.g. poverty rate) or contextual factors that have no individuallevel analogue (e.g. residential segregation, income distribution, amount of green space in urban contexts).

Nearly a century of research has documented the relation between features of the social environment (SE) and mental health and disorders $(12,13)$. With respect to depression, specific social environmental factors known to contribute to the disorder include quality of the built environment $(14,15)$, neighbourhood socioeconomic status (16) and urbanicity (17). $\mathrm{G} \times \mathrm{E}$ studies of depression, however, have thus far focused predominantly on characteristics acting at the individual or family level. Emerging evidence suggests that features of the social environment can also modify the effects of genetic factors on mental disorders including depression.

Three strands of evidence suggest that nested multilevel environmental influences may combine with genetic factors to shape the risk of mental disorders. First, genotype-phenotype associations have been very consistently demonstrated in animal models, including the serotonin transporter gene and depression and anxiety-like behaviour (18-20). Recent work by Kalin et al. is particularly relevant (21). Their findings indicate that rhesus monkey carriers of the s-allele in the promoter region of the serotonin transporter gene, rh-SLC6A4 showed increased amygdala activity in the context of stressful situations - relocation and threat - as compared with monkeys with the $1 / 1$ genotype. No increased amygdala activation was observed when rhesus monkeys were in their home cages. The authors conclude, 'These findings demonstrate context-dependent intermediate phenotypes in $\mathrm{s}$ carriers that provide a framework for understanding the mechanisms underlying the vulnerabilities of s-allele carriers exposed to different types of stressors' (p. 1021).

Second, twin studies have demonstrated that the heritability (or the proportion of phenotypical variation in a population that is attributable to genetic variation amongst individuals) of many phenotypes is modified by environmental characteristics (22). For example, genetic influences on variation in intelligence and antisocial behaviour are larger amongst individuals from higher as compared with lower childhood socioeconomic status backgrounds $(23,24)$. Genetic factors explain significant variation in cortisol reactivity to unfamiliar situations amongst young children from backgrounds characterised by low adversity; under conditions of high adversity genetic factors were not significant (25). The heritability of daily smoking has also been shown to vary by social context being highest in schools where the most popular students (26) are smokers and lowest in states with strong tobaccocontrol policies (27). Twin studies have also demonstrated social environmental modification of genetic effects, with heritability of antisocial behaviour reported to be higher amongst adolescent boys residing in socioeconomically advantaged neighbourhoods and, similarly, genetic effects on antisocial behaviour reported to be higher amongst adolescent girls residing in neighbourhoods with low levels of ethnic diversity (24).

Third, emerging evidence suggests that measured genotype-phenotype associations may also be modified by features of social environments. We have shown that specific features of county of residence (e.g. unemployment rate and crime rate) modify the association between 5-HTTLPR and post-traumatic stress disorder (PTSD) amongst adults exposed to the 2004 Florida hurricanes (28). Specifically, the ' $s$ ' allele of the 5-HTTLPR polymorphism was associated with decreased risk of PTSD (as well as major depression and generalised anxiety disorder) in the low-risk environments (e.g. low unemployment rates) but increased risk of PTSD in the high-risk environments. We have found similar results for generalised anxiety disorder (Figure 1). In multivariable models taking into account potential individual-level confounders, the interaction between the 5-HTTLPR genotype and unemployment rate was significantly $(\mathrm{p}<0.05)$ associated with risk of GAD: the $\mathrm{s} / \mathrm{s}$ genotype was associated with greater risk of GAD in high unemployment counties and with lower risk of GAD in low unemployment counties compared with other genotypes. Social environmental modification of genetic effects at the 5-HTTLPR locus have also be reported for housing type (public vs. private) and depressive symptoms amongst adolescent boys (29).

\section{Conclusions}

This area of research is novel and we can only offer early conjecture about the mechanisms through which the social environment may influence the risk of mental disorders. Clearly, much work is needed to either replicate, or refute, our work and that of others cited above and to help understand the 


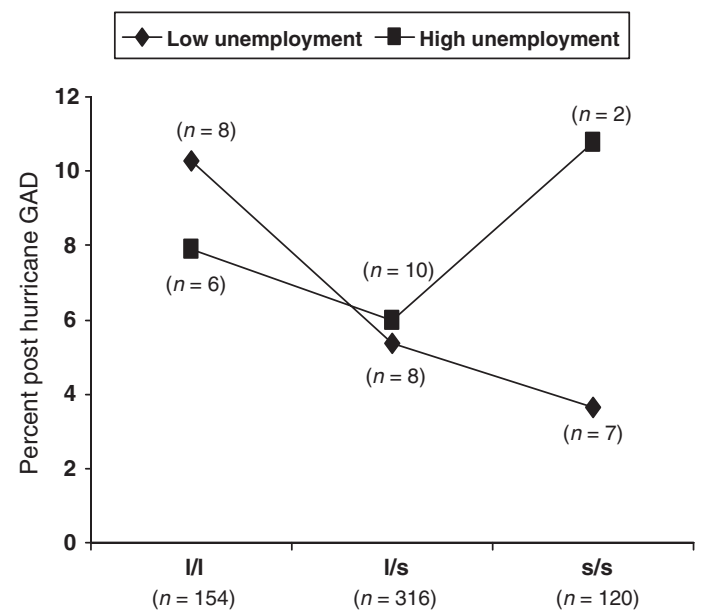

Figure 1 Prevalence of generalised anxiety disorder diagnosis(GAD) by-5HTTLPR genotype and county-level unemployment rate dichotomized as high vs. low. Logistic regression models using generalised estimating equations are adjusted for gender, age, ancestral proportion, individual-level unemployment, low social support, high hurricane exposure, other potentially-traumatic events, as well as the main effects of 5-HTTLPR and county-level unemployment. Interaction effect for 5-HTTLPR $\times$ countylevel unemployment is OR $=2.04$ ( $95 \%$ CI: $1.01,4.16)$

mechanisms that may explain these observations. However, as pointed out by Risch et al. (9), we would expect to observe the type of 'cross-over' interaction documented in our data and that of others (30) under conditions of a significant $\mathrm{G} \times \mathrm{E}$ in the absence of a genetic main effect. In addition, if it is true that features of the social environment influence genotype-phenotype associations, unmeasured environmental context could well be confounding $\mathrm{G} \times \mathrm{E}$ findings which limit the measurement of ' $\mathrm{E}$ ' to life events or other individual-level exposures.

In conclusion, these data argue for extending gene-environment interaction studies to include features of the social environment in future research. The magnitude of relative risk of disease conferred by the social environment is likely to be far less than that conferred by individual-level risk factors. However, the ubiquity of exposure to social environmental variables suggests these factors will play a substantial role in determining the population distribution of depression and other common mental disorders.

\section{Author contributions}

KCK initiated the study and wrote the first draft of this article and all authors contributed to the planning and subsequent revisions of the article.

\section{Disclosures}

We declare no competing interests.

K. C. Koenen, ${ }^{1}$ M. Uddin, ${ }^{2}$ A. B. Amstadter, ${ }^{3}$ S. Galea ${ }^{4}$ ${ }^{1}$ Departments of Society, Human Development, and Health and Epidemiology, Harvard School of Public Health, Boston, MA, USA ${ }^{2}$ School of Public Health, University of Michigan, Ann Arbor, MI, USA

${ }^{3}$ Medical University of South Carolina, Charleston, SC, USA

${ }^{4}$ Gelman Professor and Chair of Epidemiology, Mailman School of Public Health, Columbia University, New York, NY, USA

\section{References}

1 Koenen KC, Galea S. Gene-environment interactions and depression. JAMA Nov 4 2009;302: 1859; author reply 1861-52.

2 Caspi A, Sugden K, Moffitt TE et al. Influence of life stress on depression: moderation by a polymorphism in the 5- HTT gene. Science 2003; 301: 386-9.

3 Lesch KP, Bengel D, Heils A et al. Association of anxiety-related traits with a polymorphism in the serotonin transporter gene regulatory region. Science 1996; 274: 1527-31.

4 Holden C. Behavioral genetics. Getting the short end of the allele. Science 2003; 301: 291-3.

5 http://www.nytimes.com/2003/07/26/opinion/26KRAM.html?scp= $15 \&$ sq $=$ caspi $\% 20$ and $\% 202003 \&$ st $=$ cse.

6 Guttmacher AE, Collins FS. Genomic medicine - a primer. N Engl J Med 2002; 347: 1512-20.

7 Varmus H. Getting ready for gene-based medicine. N Engl J Med 2002; 347: 1526-7.

8 Guttmacher AE, Collins FS. Welcome to the genomic era. N Engl J Med 2003; 349: 996-8.

9 Risch N, Herrell R, Lehner T et al. Interaction between the serotonin transporter gene (5-HTTLPR), stressful life events, and risk of depression: a meta-analysis. JAMA 2009; 301: 2462-71.

10 http://www.nimh.nih.gov/science-news/2009/much-touted-depressionrisk-gene-may-not-add-to-risk-after-all.shtml.

11 http://www.nytimes.com/2009/06/17/science/17depress.html published June 16, 2009

12 Faris R, Dunham H. Mental Disorders in Urban Areas: An Ecological Study of Schizophrenia and Other Psychoses. Chicago: The University of Chicago Press, 1939.

13 Silver E, Mulvey EP, Swanson JW. Neighborhood structural characteristics and mental disorder: Faris and Dunham revisited. Soc Sci Med 2002; 55: 1457-70.

14 Mair C, Diez Roux AV, Galea S. Are neighbourhood characteristics associated with depressive symptoms? A review of evidence J Epidemiol Community Health 2008; 62: 940-6. 948 p following 946.

15 Kim D. Blues from the neighborhood? Neighborhood characteristics and depression Epidemiol Rev 2008; 30: 101-17.

16 Galea S, Ahern J, Nandi A, Tracy M, Beard J, Vlahov D. Urban neighborhood poverty and the incidence of depression in a population-based cohort study. Ann Epidemiol 2007; 17: 171-9.

17 Probst JC, Laditka SB, Moore CG, Harun N, Powell MP, Baxley EG. Rural-urban differences in depression prevalence: implications for family medicine. Fam Med 2006; 38: 653-60.

18 Barr CS, Newman TK, Becker ML et al. The utility of the nonhuman primate; model for studying gene by environment interactions in behavioral research. Genes Brain Behav 2003; 2: 336-40.

19 Spinelli S, Schwandt ML, Lindell SG et al. Association between the recombinant human serotonin transporter linked promoter region polymorphism and behavior in rhesus macaques during a separation paradigm. Dev Psychopathol Fall 2007; 19: 977-87.

20 Barr CS, Newman TK, Schwandt M et al. Sexual dichotomy of an interaction between early adversity and the serotonin transporter 
gene promoter variant in rhesus macaques. Proc Natl Acad Sci U S A 2004; 101: 12358-63.

21 Kalin NH, Shelton SE, Fox AS, Rogers J, Oakes TR, Davidson RJ. The serotonin transporter genotype is associated with intermediate brain phenotypes that depend on the context of eliciting stressor. Mol Psychiatry 2008; 13: 1021-7.

22 Plomin R, DeFries JC, McClearn GE, McGuffin P. Behavioral Genetics. 5th ed. New York: Worth Publishers, 2008.

23 Turkheimer E, Haley A, Waldron M, D'Onofrio B, Gottesman II Socioeconomic status modifies heritability of IQ in young children. Psychol Sci 2003; 14: 623-8.

24 Tuvblad C, Grann M, Lichtenstein P. Heritability for adolescent antisocial behavior differs with socioeconomic status: gene-environment interaction. J Child Psychol Psychiatry 2006; 47: 734-43.

25 Ouellet-Morin I, Boivin M, Dionne G et al. Variations in heritability of cortisol reactivity to stress as a function of early familial adversity among 19-month-old twins. Arch Gen Psychiatry 2008; 65: $211-8$.
26 Boardman JD, Saint Onge JM, Haberstick BC, Timberlake DS, Hewitt JK. Do schools moderate the genetic determinants of smoking? Behav Genet 2008; 38: 234-46.

27 Boardman JD. State-level moderation of genetic tendencies to smoke. Am J Public Health 2009; 99: 480-6.

28 Koenen KC, Aiello AE, Bakshis E et al. Modification of the association between serotonin transporter genotype and risk of posttraumatic stress disorder in adults by county-level social environment. Am J Epidemiol 15 2009; 169: 704-11.

29 Sjoberg RL, Nilsson KW, Nordquist $\mathrm{N}$ et al. Development of depression: sex and the interaction between environment and a promoter polymorphism of the serotonin transporter gene. Int $J$ Neuropsychopharmacol 2006; 9: 443-9.

30 Taylor SE, Way BM, Welch WT, Hilmert CJ, Lehman BJ, Eisenberger NI. Early family environment, current adversity, the serotonin transporter promoter polymorphism, and depressive symptomatology. Biol Psychiatry 2006; 60: 671-6. 